\title{
Atomism and semantics in the philosophy of Jerrold Katz ${ }^{1}$
}

\author{
KEITH BEGLEY
}

Jerrold J. Katz often explained his semantic theory by way of an analogy with physical atomism and an attendant analogy with chemistry. In this chapter, I track the origin and uses of these analogies by Katz, both in explaining and in defending his decompositional semantic theory, through the various phases of his work throughout his career.

\section{THE ANALOGY WITH PHYSICAL ATOMISM}

The first instance of the analogy with physical atomism is to be found in Katz and Fodor's seminal paper, 'The Structure of a Semantic Theory' (Katz and Fodor 1963). There they refer to hypothesized 'atomic concepts' into which meanings may be decomposed, which are represented in the theory by way of semantic markers.

The semantic markers and distinguishers are used as the means by which we can decompose the meaning of a lexical item (on one sense) into its atomic concepts, thus enabling us to exhibit the semantic structure in a dictionary entry and the semantic relations between dictionary entries. That is, the semantic relations among the various senses of a lexical item and among the various senses of different lexical items are represented by formal relations between markers and distinguishers. (Katz and Fodor 1964, 496) ${ }^{2}$

Later in the same article they point out that semantic markers are merely theoretical constructs that are used in an analogous way to that in which theoretical constructs have been used in other sciences.

a semantic marker is simply a theoretical construct which receives its interpretation in the semantic metatheory and is on a par with such scientific constructs as atom, gene, valence, and noun phrase. A marker such as (Human) or (Color) is, then, not an English word, but a construct represented by one. (Katz and Fodor 1964, 517) A similar notion of 'atomic concept' is also employed in Katz and Postal's 1964 work, An Integrated Theory of Linguistic Descriptions: 
The meaning of a lexical item is not an undifferentiated whole. Rather, it is analyzable into atomic conceptual elements related to each other in certain ways. Semantic markers and distinguishers are intended as the symbolic devices which represent the atomic concepts out of which the sense of a lexical item is synthesized. Readings represent such synthesizations of atomic concepts. (Katz and Postal 1964, 14)

In an endnote to the first sentence of this passage, they point out that, although componential analysis of the meanings of lexical items was already employed by an approach to the anthropological study of kinship terms in the 1950s, this approach had not been extended to very many other sets of lexical items nor to linguistic description more generally, and had not been integrated into the new generative linguistic descriptions that allow for the interpretation of an infinity of sentences (Katz and Postal 1964, 28, n. 7). Thus, it is clear that they saw the extension of this method to lexical items more generally, and its relation to the new Chomskyan grammar, as constituting part of the novelty of the theory.

\section{THE FREGEAN ANALOGY WITH CHEMISTRY}

In an article from December 1964, 'Semantic Theory and the Meaning of "Good", Katz extended the analogy between conceptual and physical atoms, to include an analogy with chemistry. This is an analogy between a reading, that is, a theoretical representation of the sense of an expression, composed of semantic markers, and a chemical formula for a molecule, in respect of the manner in which they represent the structures of their respective objects:

[Semantic markers] are to be regarded as constructs of a linguistic theory in just the sense in which terms like 'force', 'mass', 'molecule', etc. are accepted as labels for scientific constructs in physical theory. There is here a strong analogy between the manner in which a reading for a sense of a word or expression represents its structure of concepts and their interrelations and the manner in which a chemical formula for a molecule of a substance represents its structure of atoms and the bonds between them. Both employ theoretical constructs of a scientific theory and a schema of representation to exhibit the elements and relations out of which a compound entity is formed. (Katz 1964, 744)

Katz later makes similar statements in his book The Philosophy of Language (1966) and provides there in addition the following example of such a formula, a diagram for a molecule of ethyl alcohol:

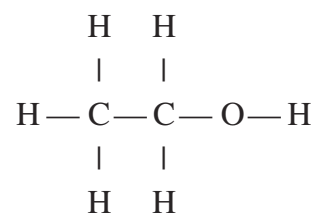

(Katz 1966, 156; cf. Katz [1966] 1970, 187) 
The analogy with chemistry was quite important for Katz, and it continued to appear in various forms in publications throughout his career, the latest usage being in an article from 1992. ${ }^{3}$ Although Katz does not say so explicitly, I find it likely that the analogy was inspired by a similar analogy used by Gottlob Frege in 'On Concept and Object' (1892). There is, I think, good circumstantial evidence for this claim in that the analogy with chemistry certainly began to become important for Katz at just the time that he was beginning to read Frege closely. We should first note that later, in the preface to Semantic Theory (1972), Katz acknowledges a general debt to Frege, but also his and Fodor's earlier ignorance of the details in Frege's work:

the more our approach was worked out, the more it was found to embody versions of Frege's principles. Fodor and I were originally unaware of the extent to which doctrines of ours were often replicas of Frege's. In the present book, I have tried to indicate some of the debt that empirical semantics (in our sense) owes to him. (Katz 1972, xxiv)

The first of these indications, following the statement just quoted, is in regard to Frege's approach to the question 'What is Meaning?' (Katz 1972, 3n), a question that we will return to presently. The second indication is in regard to the principle of effability (Katz 1972, 19). ${ }^{4}$ A third is in regard to the notion of a primitive semantic marker, which is the theoretical representation of an atomic concept. Katz makes the point here that the inventory of such markers or the atomic concepts that they stand for cannot be set out in advance of the theory of which they are a part, but only as 'required in the formation of dictionary entries' (Katz 1972, 38). To this, Katz provides a footnote in which he quotes from Frege's 'On Concept and Object' as follows:

my explanation is not meant as a proper definition. One cannot require that everything shall be defined, any more than one can require that a chemist shall decompose every substance. What is simple cannot be decomposed, and what is logically simple cannot have a proper definition. Now something logically simple is no more given us at the outset than most of the chemical elements are; it is reached only by means of scientific work. If something has been discovered that is simple, or at least must count as simple for the time being, we shall have to coin a term for it, since language will not originally contain an expression that exactly answers. On the introduction of a name for something logically simple, a definition is not possible; there is nothing for it but to lead the reader or hearer, by means of hints, to understand the words as is intended [Frege 1952, 42-3]. (Katz 1972, 38n)

Katz' first published reference to the source of this quotation and, indeed, his first direct references to Frege ${ }^{5}$ are given in his book The Philosophy of Language (Katz 1966, 47n), which was in press before October 1965 (Katz 1965, 600n). Moreover, it seems likely that he was asked by Arthur Danto, before the autumn of 1964, to begin writing an essay for inclusion in The Harper Guide to Philosophy, which he probably first submitted by the end of the summer of 1965, if not earlier. ${ }^{6}$ In that essay, Katz further develops the analogy with atomism, which we will discuss presently. However, 
due to approximately a five-year delay, it is not until 1971 that this essay is published in the form of a book, The Underlying Reality of Language and its Philosophical Import. This short introductory book turns out to be quite programmatic, and it came just a few months before Katz published his main technical work, Semantic Theory (1972), to which the former work already contained many references added in footnotes. ${ }^{7}$ The 1971 book also contains a short fragment of the same quotation from Frege's 'On Concept and Object' as that which is quoted in Semantic Theory, and in the same connexion regarding primitive semantic markers: 'As Frege once observed, “... something logically simple is no more given us at the outset than most of the chemical elements are; it is reached only by means of scientific work."' (Katz 1971, 101). This indicates that Katz certainly had read 'On Concept and Object' at least five years before June 1971, and probably before October 1965 since he refers to the source in The Philosophy of Language, and perhaps as early as the summer of 1964, given that he had been recruited to write the essay in which he quotes Frege's analogy. That is, early enough for it to have inspired the analogy with chemistry that appears in Katz' article published in December of that year (Katz 1964).

\section{THE DEMOCRITEAN APPROACH}

Beginning with his short book in 1971, Katz adds a further element to the analogy through conceiving of his semantic theory as being part of a Democritean linguistic theory. This element of the analogy with atomistic theory serves to emphasize the appearance-reality distinction that is integral to the theory, in contrast to some other linguistic theories. Here, Katz takes the Democritean concept of matter to be a paradigm case:

The Democritean concept of matter originated as a purely hypothetical postulation. Initially, it could only have seemed the most extravagant of fancies. It proposed to populate the universe with unbelievably many new objects. Such objects were, moreover, supposed to be invisible and yet to provide the true understanding of visible phenomena. Finally, to add insult to injury, the concept flew in the face of the plain testimony of sense experience. But when it proved to yield better predictions and explanations of the observable behavior of physical objects and substances than the concept of continuity, it received scientific acceptance. The continuity hypothesis, which once must have seemed the last word in sober science, became relegated to the status of a depiction of appearance. (Katz 1971, 3)

Katz is careful to show how the Democritean approach contrasts with other philosophical approaches. For example, he says that it contrasts with the early Wittgenstein's philosophy in respect of the latter's 'assumption that logical form is [inaccessible]' (Katz 1971, 11). He quotes Wittgenstein's famous clothing metaphor for this point from Tractatus Logico-Philosophicus, 4.002:

Language disguises thought. So much so, that from the outward form of the clothing it is impossible to infer the form of the thought beneath it, because the 
outward form of the clothing is not designed to reveal the form of the body, but for entirely different purposes. (Wittgenstein 1922, 61-3, quoted in Katz 1971, 9-10)

Katz replies to this by tailoring the clothing metaphor to his own Democritean approach as follows:

To vary Wittgenstein's metaphor somewhat: While it is true that language disguises thought, the disguise fits in such a way as to enable us to frame for ourselves a facsimile of the form of the body hidden beneath if we are willing to penetrate the disguise in the way physicists penetrated the disguise in which nature presents matter to us in sense experience.

Thus, a Democritean theory of language also contrasts with the later philosophy of Wittgenstein. Within the framework of a Democritean theory, we conceive the problem of understanding the logical features of language as a problem of theory construction. (Katz 1971, 12)

This variation would appear to be cut from similar cloth to that of Frege's clothing metaphor in 'The Thought' (1918):

The thought, in itself immaterial, clothes itself in the material garment of a sentence and thereby becomes comprehensible to us. We say a sentence expresses a thought. (Frege [1918] 1968, 511)

Katz takes somewhat of a middle position. That is, although the material garment is what enables us to frame a 'facsimile' of what it clothes, it is nonetheless a disguise that must be penetrated by constructing a Democritean theory of what lies beneath its covering. Katz does provide a reference to a translation of Frege's article, but only at a much later point in the book, where he agrees with Frege's non-psychological use of the word Gedanke (thought) (Katz 1971, 121n). He quotes the passage from the Tractatus in a number of other publications, ${ }^{9}$ but never quotes the concomitant passage from Frege's article. ${ }^{10}$ So, it is uncertain whether Katz ever noticed a similarity with the passage from Frege.

Katz takes the rationalist position, inspired by the work of Noam Chomsky, that since users of a language do indeed often manage to penetrate the orthographical and phonological disguises, we can frame a 'facsimile' of the underlying form through providing a theory of their competence to do so. This is also spelt out in terms of a contrast with what Katz calls non-Democritean theories. These theories, such as the pre-Chomskyan taxonomic theories of grammar, naively rely merely upon the manifest features of utterance-tokens when forming theories of sentence types (Katz 1971, 19). As Katz put it:

the non-Democritean assumption about the nature of language leads to grammars whose rules only permit descriptions of linguistic features observably manifest in utterances of sentences, while the Democritean assumption leads to grammars whose rules also permit descriptions of linguistic features that are not observably manifest. (Katz 1971, 31)

Katz took Chomsky's transformational model of grammar to be the embodiment of such a Democritean method and to be part of a tradition stretching back to 
the universal grammar of the seventeenth-century Port-Royal grammarians (Katz 1971, 46). Katz also contrasts the Democritean approach with the non-Democritean approach to the question 'What is Meaning?', which he calls 'the big question of semantics' (Katz 1971, 84). Non-Democritean theories, he says, tend to misconstrue the question as a request for a direct and straightforward answer (Katz 1971, 85-6; Katz 1972, 3). He lists some notable examples of such answers to the question:

These include the [Platonic] answer that meanings are eternal archetypes; the Lockean answer that meanings are the mental ideas for which words stand as external signs; the answer that meanings are the things in the world to which words refer; the Wittgensteinian answer that meaning is use; the behaviorist answer that meanings are the stimuli that elicit verbal responses; the introspectionalist answer that meanings are mental images associated with verbal behavior; and so on. (Katz 1971, 85)

In contrast, the Democritean approach begins by reversing the order of investigation. That is, not by first attempting directly to state what meaning is in terms of something else that is better or more explicitly known to us antecedent to providing a theory of meaning, rather, by seeking to construct a theory of meaning before subsequently attempting to say more about what meaning must be in order to satisfy this theory as its object. Katz motivates this approach through a comparison with the history of other sciences:

Imagine what would have happened if ancient astronomers had insisted on knowing what sorts of things planets are before trying to describe their movements. Or, better yet, suppose mathematicians had insisted on a direct answer to the question 'What are numbers?' before trying to explain arithmetic properties and relations like 'is the sum of', 'is the square root of', and 'is a prime number'. We would now be without a theory of arithmetic (i.e., number theory). $(\text { Katz 1971, 94) })^{11}$

A corollary of this is that there is no room in this approach for philosophical scepticism about planets and numbers within astronomy and mathematics; these disciplines seek merely to provide adequate theories of what appears to us, that is, the phenomena. Analogously, Katz seeks to silence the sceptic of semantics by doing semantics; to refute them thus (cf. Katz 1972, 2).

Katz is led by this diagnosis 'to begin with the assumption that "What is meaning?" is a request for a semantic theory' (Katz 1972, 3). This is the point from which he sets off in his main technical work Semantic Theory (1972). Here he follows again the example of the Democritean theory of matter, which he explains as follows:

Physicists were in no position to say what matter was until they identified a wide range of phenomena exhibited in the behavior of matter and ascertained many of the significant empirical facts in each case. These various phenomena (diffusion, expansion, interpenetration, conduction, etc.) demarcated the domain for a theory of matter by bringing together the properties that such a theory had to explain. It then became possible to compare different conceptions of the 
nature of matter in terms of their explanatory adequacy within this circumscribed domain. We can say, therefore, that the Democritean theory was arrived at by the construal of the questions 'What is diffusion (of matter)?' 'What is expansion (of matter)?' 'What is interpenetration (of matter)?' and so on as components of the question 'What is matter?' This reflects the common practice in science of breaking down a large, general question into narrower, more specific ones. The answers to these questions then form integral parts of the answer to the general question because the phenomena about which they ask are within the appropriate explanatory domain. (Katz 1972, 4)

Analogously to this approach to matter, Katz breaks the big question of semantics 'What is meaning?' into a non-exhaustive list of fifteen sub-questions that identify the most prominent sense properties and relations pertinent to a theory of meaning: synonymy and paraphrase, similarity and difference, antonymy, superordination, meaningfulness and anomaly, ambiguity, redundancy, analyticity and metalinguistic truth, contradiction and metalinguistic falsehood, syntheticity, inconsistency, entailment, presupposition, possible answerhood and self-answerhood (Katz 1972, 4-6). For Katz, providing a semantic theory is to provide an integrated theory of these sense properties and relations, which the theory represents in terms of relations between semantic markers.

\section{THE ANALOGICAL DEFENCES OF THE THEORY}

These analogies with atomism and chemistry later become important for Katz' defence of the theoretical approach. For example, in an article by Chomsky and Katz from 1974, the authors reply to what they take to be a Quinean misinterpretation of linguistics that was put forward by Stephen Stich. Stich complained that Katz seemed not to have sufficient evidence for his conclusions given that Stich himself was not able to derive as much from the same evidence using his own (non-Democritean) method. Chomsky and Katz reply to this by stating that there are always at least two ways to react to such a poverty of evidence:

we can point out that some people may well be interested in making hypothetical inferences about underlying causes on the basis of certain evidence, while others with different interests and outlook may choose to restrict their attention more narrowly to the evidence. We can certainly imagine that some early physicists might have been quite happy to accept diffusion and similar phenomena at face value, chiding their Democritean colleagues for 'flamboyant portraits' of atoms. (Chomsky and Katz 1974, 365)

The point here being that, unless one goes beyond the evidence and hypothesizes underlying linguistic form, one will be stuck at the naïve and non-Democritean level of manifest utterances.

The analogy with chemistry later forms an important part of Katz' defence against David Lewis' (in)famous criticism of his semantic theory, which Lewis puts forward at the beginning of his paper 'General Semantics' (1970). There 
Lewis refers pejoratively to the symbolism of the theory as 'Semantic Markerese', a characterization that has been parroted for decades following. ${ }^{12}$ Indeed, his argument relies upon this erroneous characterization of Katz' theoretical symbolism as being a mere language:

Semantic markers are symbols: items in the vocabulary of an artificial language we may call Semantic Markerese. Semantic interpretation by means of them amounts merely to a translation algorithm from the object language to the auxiliary language Markerese. But we can know the Markerese translation of an English sentence without knowing the first thing about the meaning of the English sentence: namely, the conditions under which it would be true. Semantics with no treatment of truth conditions is not semantics. (Lewis 1970, 18)

Indeed, as Lewis goes on to say, if this were the case, one might as well have translated the English sentence into Latin for all the good it would do, because we would then be relying on 'our tacit competence as speakers' of this language, or our ability to do so-called 'real semantics' for the same by providing truth conditions (ibid., 18-19).

Katz pointed out in his responses that Lewis completely overlooked or ignored the fact that the semantic theory is a theory and, as such, is distinct from a mere artificial language. Apart from this necessary emendation in the spirit of charity, Katz grants that, equipped with a semantic theory, the reading of an English sentence can be known without knowing the meaning of the English sentence. However, he points out that this is merely because it can be known, in a purely formal and procedural manner, via certain projection rules, that the theory maps a certain reading $\mathrm{R}$ onto a certain sentence S. However, this does not show what Lewis intended it to, because, as Katz explains:

a person who does not know semantic theory cannot know what claims $\mathrm{R}$ makes about the meaning of $S$. Since semantic theory provides the intended interpretation for the semantic portion of the grammar of a natural language, the reading $\mathrm{R}$ is merely a concatenation of meaningless symbols unless interpreted under an appropriate semantic theory. Similarly, someone may know that a chemical description of some covalent bond represents it as

$$
\begin{gathered}
\mathrm{H} \\
\mathrm{H}: \overrightarrow{\mathrm{C}}: \mathrm{H} \\
\cdots \\
\mathrm{H}
\end{gathered}
$$

without knowing what this symbolism asserts about the nature of the bond. (Katz $1975,108-9)^{13}$

So, it is important to stress, the readings produced by the semantic theory make claims when interpreted within the theory. That is, they are bypotheses about underlying structures, not mere translations. Lewis' argument failed to show what he intended it to because, as Katz elucidates by way of the analogy with chemistry, 'the relation between a sentence of a natural language and its reading(s) is no more translation 
than the relation of [a chemical description] to a covalent bond is translation' (Katz 1975, 110).

For one matter, as Katz points out, in contrast to the theoretical 'reading of' relation, the 'translation of' relation is symmetrical. That is, 'if $S_{1}$ is a translation of $S_{2}$, then $S_{2}$ is a translation of $S_{1}$ but the latter is asymmetrical, i.e., if $R$ is a reading of $S$, then $S$ is not a reading of $R^{\prime}$ ' (Katz 1975,110). So, Lewis would have needed to prove, at the very least, that the 'reading of' relation is symmetrical. However, since a reading is part of a hypothesis generated by a theory of semantic competence, it contains or codifies information that is not directly contained in the sentence onto which it is mapped. So, it follows that such a proof is not possible, or at least not possible in most instances.

Lewis' further and somewhat glib remark that 'Semantics with no treatment of truth conditions is not semantics' is no objection to Katz at all, because it relies on an ambiguous antecedent usage of the word 'semantics' (cf. Katz 1972, 182), which Lewis himself acknowledged existed in the literature of the time. Katz' theory is simply not aimed at explaining the same phenomena. Hence, Lewis merely begs the question (Katz 1975, 114). ${ }^{14}$ That is, he essentially says nothing more than that 'The theories of meaning with no treatment of truth conditions are not the truthconditional theories of meaning', which does not even have the virtue of being false. ${ }^{15}$

\section{SWIMMING IN THE 'PLATONIST WHIRLPOOL'}

In 1977, a major change takes place in Katz' approach. Previously, he had adopted an anti-sceptical and non-reductionist method, as part of the Democritean approach, regarding the objects and posits of semantic theory. However, he had also expressed difficulties with, among others, some realist approaches such as the Platonist approach, calling it on various occasions 'wholly uninformative' (Katz and Fodor 1962, 212), ${ }^{16}$ 'empirically inadequate' (1964, 762), 'too vague and speculative' $(1971,85)$ and even described the later Wittgenstein as attempting 'to steer a safe course between the formalist rock and the Platonist whirlpool' $(1971,11)$.

Despite these earlier attitudes, in his article 'The Real Status of Semantic Representations' (1977), Katz broaches the topic of Platonism once again and reveals that he is preparing a work in which he will 'try to develop a tenable version of the Platonist position' (1977, 564n). ${ }^{17}$ This is what eventually becomes his book Language and Other Abstract Objects (1981) in which he develops a realist distinction between knowledge of language, in the sense of competence, and the language of which it is knowledge, which he considered to be an abstract object. A Chomskyan conceptualist theory of language is a theory of the former, a Platonist theory of language is a theory of the latter.

The explicit analogies with atomism and chemistry are notably absent during this transitional period, but soon return. First, in his article 'Common sense in semantics' (1982), the analogy with chemistry remains a means of explaining the decomposition of senses:

we have to go beyond a notational scheme consisting, in effect, of numericals functioning as bare names of senses. We require a scheme that describes the structure of senses in the decompositional way that chemical diagrams describe 
the molecular structure of compounds. Our first approximation is inadequate because it only provides names for senses taken as unanalyzed wholes.

In going beyond this first approximation, we are going beyond both Fregean and standard predicate calculi theories of the logical structure of natural languages. (Katz 1982, 198)

Here, Frege's analogy with chemistry (if, as I suggested earlier, it was originally his) is turned against him. The 'numericals' mentioned here (later called 'numerals', cf. Katz 1990, 65) are intended to illustrate elements of a Fregean theory of sense. The point being that such unary designators standing for unanalysed whole senses are unable to describe the decompositional structure sufficient for subordination, antonymy and the other sense properties and relations. These designators are only capable of representing bare sameness and difference of sense, for example, $\{1\}=$ $\{1\}$ and $\{1\} \neq\{2\}$ and so on. ${ }^{18}$ While this was enough to enable Frege to provide solutions to his famous problems regarding co-referential names and opaque contexts, it is not sufficient to describe the other sense relations. ${ }^{19}$

To see why this is, consider the following simple examples, which Katz uses in a later work. If one attempts to represent the synonymy between 'sister' and 'female sibling', their senses will be designated by different numerals and hence they will be marked as non-synonymous. If one attempts to represent the antonymy between 'open' and 'closed' in this manner, one will not be able to mark the difference between this kind of sense relation and that between the merely non-synonymous 'open' and 'destroy' (Katz 1990, 65).

It is clear from this that Katz' basic decompositional approach remained largely the same but that he was also beginning to distinguish his theory more carefully from its earlier Fregean influences. In his book Cogitations (1986), the analogy with the Democritean theory of matter is also put to work against the later Wittgenstein's criticisms of the notion of analysis; an account of these criticisms is to be found in the previous chapter of the present volume (cf. Coliva 2020, 304ff.), including PI $\ 47$ to which Katz responded as follows:

Everything that Wittgenstein says about the analysis of language can also be said about the analysis of physical substances. Physical analysis cannot employ absolute notions of simplicity and compositeness, either, and for the same logical reasons. But physicists from Democritus to Dalton employed a notion of the components of matter that was relativized to the scientific aim of uncovering the truth about its behavior. As a consequence, what physicists said about the nature of matter on the basis of scientific investigation enjoyed a derivative privileged status with respect to counter claims made on other bases. One couldn't sensibly reply to the Democritean theory, 'Matter? Well, it's composed of atoms and molecules, relative to findings based on investigations aiming at the truth, but, of course, it isn't relative to findings based on investigations with other aims.' (Katz 1986, 153)

That is, in the case of semantic theory, the analysis or, rather, the decomposition, is carried out just as far as is required to define the various sense properties and relations over the relevant atomic concepts, and thereby 'to state true laws about 
the properties of sentences' (ibid.). Any less and the theory would lack explanatory power, any more and the theory would contain redundant elements. This is what 'defines the enquiry itself' (Katz 1986, 153-4).

In The Metaphysics of Meaning (1990), Katz seems to take a slightly broader view of the application of the term 'Democritean' (cf. Katz 1990, 53-7). Here he talks about Democritean approaches in both grammar and logic and reflects on their shortcomings when developing his Democritean approach to semantics. In earlier works, he had already applied the term to the Chomskyan rationalist approach to grammar. Here he says that the approaches of Frege and Russell could be seen as 'a corresponding 'Democritean' tradition in modern logic which advocates posits of underlying logical structure to overcome the insufficiency of surface grammar to account for certain logical inferences' (Katz 1990, 53). Here 'Democritean' means merely the recognition that there must be a distinction between surface and deep structure in the various areas in which it is applied. Katz' approach to semantic theory draws on both traditions.

\section{BETTER SEMANTICS THROUGH CHEMISTRY}

The final mention of both the analogies with chemistry and atomism occurs briefly in Katz' article 'The New Intensionalism' (1992):

Having no conception of analysis on which syntactically simple words in sentences like ['The spot is blue', 'The spot is red', 'Bachelors are unmarried', 'Red is a colour', 'Squares are rectangles', 'John is a bachelor', 'John is unmarried'] can have complex sense structure, Tractarian semantics had no access to the structure which actually determines the inferential powers of those sentences. Tractarian semantics is like chemistry prior to the period of the atomic theory; decompositional semantics is like chemistry afterward. (Katz 1992, 702)

The difficulty to which Katz is referring here is usually referred to as the colour incompatibility problem or the colour exclusion problem. ${ }^{20}$ That is, for example, the theoretical problem of marking the incompatibility relations between sentences such as 'The spot is blue' and 'The spot is red', given that their conjunction does not have the form of a logical contradiction, for example, ' $p$ and not-p'. Katz' solution manages to link the senses of 'red' and 'blue' in such a way that avoids positing that the senses of the colour terms are explicitly contained in each other in isolation. Instead, it is in so far as such terms are involved in sentences that such relations hold. As Katz put it: 'Compositionality makes the difference' (Katz 1998, 572-3). The theory represents such structures through four interlinked formal devices, which Katz calls the antonymy operator, antonymous n-tuples, categorized variables and selection restrictions.

I will now provide a brief exposition of the interlinked formal devices that Katz employs to implement his solution to the problem. The first is the antonymy operator 'A/...', which is analogous to the negation operator in logical calculi; the difference is that negation is an external operator that toggles the truth value of its argument, that is, a proposition, from true to false or false to true, whereas the antonymy 
operator in Katz' semantic theory is an internal operator that toggles from one semantic marker to others within the same antonymous $n$-tuple. ${ }^{21}$ An antonymous $n$-tuple is simply a set of markers that all contain the same superordinate marker; so, the antonymous $n$-tuple comprising the complex markers that contain the marker for the sense of 'colour', includes the markers for the senses of 'red', 'blue', 'green' and so on. The markers are automatically grouped in this way in virtue of the fact that each of them contains the superordinate marker '(colour)'. Katz states the general form of an antonymous $n$-tuple as: ' $\left(\mathrm{M}^{\left(\alpha_{1}\right)}\right),\left(\mathrm{M}^{\left(\alpha_{2}\right)}\right), \ldots,\left(\mathrm{M}^{\left(\alpha_{n}\right)}\right)$ ' $(\operatorname{Katz} 1972$, 52 ), where the semantic marker ' $M$ ' (in this context) represents the superordinate sense component and each $\alpha$ represents a different subordinate sense component, and he defines the notion of an antonymous $n$-tuple as follows:

Two semantic markers belong to the same antonymous $n$-tuple of semantic markers if and only if one has the form $\left(\mathrm{M}^{\left(\alpha_{i}\right)}\right)$ and the other has the form $\left(\mathrm{M}^{\left(\alpha_{j}\right)}\right)$, where $i \neq j$ and $1 \leq i \leq n$ and $1 \leq j \leq n$. (Katz 1972, 52) $)^{22}$

The next piece in the solution is the use that Katz makes of categorized variables and selection restrictions. A categorized variable awaits a semantic value given by another part of the reading of a sentence; they are categorized according to the functional notation of the syntactic theory being used. The variable is also given a selection restriction, for example, '<(colour) >', which constrains the selection of the marker that will replace the variable. So, any semantic marker that replaces the categorized variable must include the superordinate marker '(colour)'. That is, the marker must be one that is taken from the antonymous $n$-tuple comprising the markers for the colour senses. Categorized variables are notated in the following fashion:

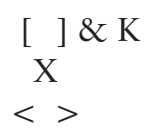

The square brackets include the functional syntactic notation that specifies a particular node of the underlying phrase marker for a sentence, for example, 'subject of' is represented as '[NP, S]', the function from a noun phrase to a sentence. It is the semantic reading (or a component thereof) ${ }^{23}$ of this node of the underlying phrase marker, represented as structured semantic markers, which will be substituted for the variable in a derived reading for the sentence (or higher-level constituent) as a whole. The angled brackets include the semantic selection restriction for the variable, for example, '<(colour)>' (cf. Katz 1972, 104ff.).

Although the sense of 'red' does not contain the sense of any other specific colour term, it nonetheless excludes the sense of any antonymous colour term. The reading for 'red' is given in the form of the complex semantic marker ' $(($ red $),(\mathrm{A} /(\mathrm{X})))$ (colour))', ${ }^{24}$ where ' $\mathrm{X}$ ' is a categorized variable with ' $<$ (colour) $>$ ' as its selection restriction, and the function ' $[\mathrm{F}]$ ' as its syntactic function. The '[F]' function picks out the semantic markers of the colour term in the predicate of a verb phrase, for example, the reading for 'blue'. For instance, only the reading for some other colour term, for example, 'blue', could replace ' $\mathrm{X}$ ' when 'red' is involved in a sentence 
such as 'Red is not blue'. The rules of Katz' semantic theory would then mark this sentence as being analytic, and a sentence like 'The spot is red and blue' as being contradictory on a sense. ${ }^{25}$ Thus, the theory provides a theoretical explanation of such properties.

Katz' Democritean semantic theory allows for the decompositional representation of what were considered by the early Wittgenstein to be independent, non-complex simples, as instead having a minimal internal complexity consummate with the relations into which the senses of such terms enter. As I have shown in this chapter, this approach to semantic theory was both explained and defended by Katz, throughout its various phases of development over more than thirty years, often by way of analogies with physical atomism and chemistry.

\section{NOTES}

1. A penultimate draft of this chapter was read at the work-in-progress árd-seimineár at the Trinity Plato Centre, Trinity College Dublin, in October 2019. I am especially grateful for the helpful discussion and for comments that I received from Vasilis Politis, Peter Larsen, Margaret Hampson and Simone Nota.

2. I quote instead from Katz and Fodor's revised version of their paper included in their edited volume, The Structure of Language, published in 1964. Although they note that the article has been reprinted from the 1963 original, they made quite a number of changes and corrections throughout but make no note of this. Importantly, here the infelicitous phrase 'the meaning of one ense [sic] of a lexical item' $(1963,185-6)$ is replaced with 'the meaning of a lexical item (on one sense)' (1964, 496), because, of course, senses themselves do not have meanings, rather, they are meanings.

3. The analogy with chemistry has been noticed by Arnold M. Zwicky, who quotes from Katz $(1966,156)$ and pursues a related thesis (Zwicky 1973, 476). It was also noticed by Keith Allan ([1986] 2014, 317), who mentions Katz' article (1964, 744), but grossly misinterprets the analogy there: 'His semantic markerese is like chemical formulae in that it translates into English' (Allan [1986] 2014, 317).

4. D. Terence Langendoen has recently claimed that it was instead Edward Sapir's principle of formal completeness that was 'reinterpreted' by Katz as the principle of effability (Langendoen 2018, 261). However, this is not what Katz himself says in print. See my review of the edited volume that contains Langendoen's article (Begley 2019). It appears that Langendoen $(2010,141 \mathrm{n})$ overinterpreted a claim made by Von Fintel and Matthewson $(2008,142-3)$, whom he subsequently neglected to cite in 2018. Their claim is in fact much weaker: 'The effability idea has been around since at least Sapir [1924]' (2008, 143, emphasis added). Nevertheless, they also overlook an attribution by Katz of the principle to Frege in 1923 (Katz 1976, 36).

5. 'Fregeans' are mentioned once before this, but merely as one group in a list of the proponents of various positions (Katz and Fodor 1962, 197). Frege's work is, of course, mentioned by other authors in Fodor and Katz (1964).

6. In the preface of the book that resulted from this project, The Underlying Reality of Language and its Philosophical Import, dated June 1971, Katz reports that he originally wrote the book as an essay 'about five years' previous for inclusion in The 
Harper Guide to Philosophy (Katz 1971, vii), edited by Arthur Danto. This was one of a number of guidebooks conceived by Fred Wieck, an editor at Harper. Robert Paul Wolff, the author of another of the essays, reports that he was the last to be recruited by Danto for the project, when he arrived at the Columbia philosophy department in the autumn of 1964, after Danto had been turned down by Isaiah Berlin. Danto requested that Wolff submit his essay for the end of the summer of 1965, which he did (Wolff 1998, x-xi; Wolff 2010; Wolff 2019). So, it is likely that Katz submitted his essay at the same time or before, given that he was recruited before Wolff.

Although Katz noted the guide as being 'in press' in 1968 (Katz 1968a, 493), delays ensued. Another section author, Bernard Williams, later reported that he and some of the other authors even took to calling the guide 'Harper's Bazaar' (Williams 1993, xi). In 1970, it was suggested by Wolff that each essay instead appear as a short book. He lists the titles of the other books that came out of the project, apart from his own In Defense of Anarchism and Katz' book, as: 'What Philosophy Is, by Arthur Danto; Observation and Explanation, by Norwood Hanson; [. . .] Problems of Mind, by Norman Malcolm; What is Knowledge, by David Pears; The Philosophy of Logic, by Hilary Putnam; Morality: An Introduction to Ethics, by Bernard Williams; and Art and Its Objects; by Richard Wollheim' (Wolff 1998, xii). Some of these were republished in the UK by Allen \& Unwin, with Katz' book retaining its title as a subtitle and taking the new title Linguistic Philosophy.

7. In a letter to Fritz Staal at the end of August 1968, Katz reported that he had worked on his book over the summer, completing chapters $1-4$, and had written but not edited a further five (!) chapters, which he planned to finish over the next semester and then send a resulting '800-page opus' to Staal (Katz 1968b). Semantic Theory (1972) has eight chapters.

8. Translated elsewhere as: 'The thought, in itself imperceptible by the senses, gets clothed in the perceptible garb of a sentence, and thereby we are enabled to grasp it. We say a sentence expresses a thought' (Frege 1997, 328).

9. For example, Katz (1981, 163; 1990, 67); and partially in (1992, 693).

10. It is uncertain what connection, if any, there is between the two passages. One might be tempted to think that because the Tractatus was published after Frege's article, it includes a response to the latter. However, Wittgenstein's above quoted remarks from 4.002 appear with minor differences in 4.0014 and 4.00141 of an earlier manuscript, MS104 on page 36 (Wittgenstein 2015). Also included there is another relevant remark that is not preserved in the Tractatus: 'Thus the outward aspect of ordinary language makes every kind of illusion and confusion possible' (Wittgenstein 1971, 4.0015). On some views, this material may originally date to Wittgenstein's time in Norway, between October 1913 and June 1914 (Kang 2005, 6), and, on others, at least between October 1915 and March 1916 when added to MS104 (McGuinness 2002, 266), although there is still much disagreement. I do not intend to adjudicate on the matter here.

Frege and Wittgenstein met and engaged in correspondence but, from what remains of this, the clothing metaphor is not apparent. However, the metaphor was indeed used much earlier by Frege and so may have been mentioned in conversation with Wittgenstein during the intervening period. The following rather clear and pertinent example comes from a posthumously published paper, entitled 'Logic', dated to 1897, in which Frege notes a 'difficulty': 
grammar, which has a significance for language analogous to that which logic has for judgement, is a mixture of the logical and the psychological. If this were not so, all languages would necessarily have the same grammar. It is true that we can express the same thought in different languages; but the psychological trappings, the clothing of the thought, will often be different. (Frege [1897] 1979, 142; cf. 135, 185; also printed in Frege 1997, 243; cf. 361)

Frege had earlier used a similar clothing metaphor regarding concepts, in The Foundations of Arithmetic (Die Grundlagen der Arithmetik, 1884): 'Often it is only through enormous intellectual work, which can last for hundreds of years, that knowledge of a concept in its purity is achieved, by peeling off the alien clothing that conceals it from the mind's eye' (Frege 1997, 88). Wittgenstein is known to have had a copy of the Grundlagen at Cambridge (now preserved in the Russell Archives), which he abandoned there when he returned to Norway in October 1913 (Kienzler 2011, 81-2). Another possible influence upon Wittgenstein may have been Heinrich Hertz. This is also noted by Hacker $(1972,12)$. In the closing remark of Hertz' introduction to a collection of papers he says:

scientific accuracy requires of us that we should in no wise confuse the simple and homely figure, as it is presented to us by nature, with the gay garment which we use to clothe it. Of our own free will we can make no change whatever in the form of the one, but the cut and colour of the other we can choose as we please. (Hertz [1892] 1893, 28)

11. Katz here repurposes without citation Quine's example of ancient astronomy (1953, 47), which he later quotes for the same purpose (Katz 1972, 9).

12. For example, when Keith Allan says: 'His semantic markerese is like chemical formulae in that it translates into English' (Allan [1986] 2014, 317), cf. note 3 above.

13. The diagram's numbering has been removed.

14. Further, as Gilbert Harman makes clear in 'Meaning and Semantics' (1974), Lewis' argument can also be applied to truth-conditional theories of meaning:

Similarly, there is a sense in which we can know the truth conditions of an English sentence without knowing the first thing about the meaning of the English sentence. To borrow David Wiggins's example, we might know that the sentence "All mimsy were the borogroves" is true if and only if all mimsy were the borogroves. However, in knowing this we would not know the first thing about the meaning of the sentence, "All mimsy were the borogroves." (Harman 1974, 6)

Wiggins' example is to be found in a footnote in his 'On Sentence-Sense, WordSense, and Differences of Word-Sense' (1971), which comments on the Vienna Circle's verifiability criterion of meaning:

I surely cannot say or explain what All mimsy were the borogroves means by saying that this sentence will be true if and only if everything satisfies the open sentence if $X$ is a borogrove then $X$ is mimsy. And it is certainly a part of what would still be lacking in this explanation that it gives no idea at all of what investigations with what outcome would count for or against the assertion. (Wiggins 1971, 19n) 
It is somewhat ironic that both Wiggins and, following him, Harman misquoted from the poem 'Jabberwocky' by Lewis Carroll. The word is instead 'borogoves'. Although the borogroves sounds like a miserable place to be, perhaps near the wabe and where one might find a mimsy borogove, it is uncertain whether the borogroves could really be mimsy at all. Perhaps more ironically, the word first appears in Carroll's earlier 'Stanza of Anglo-Saxon Poetry' (1855), where he provided a literal English translation for the 'nonsense' sentence containing it: 'all unhappy were the parrots' (Carroll [1855] 1932, 141).

15. Admittedly, Lewis seems to rely upon his impression of the early Katz and Postal version of the theory from 1964, and it is not until the Democritean approach is spelt out by Katz in 1971 that its differences with other, non-Democritean approaches generally would have become clear. However, this kind of misunderstanding of Katz has continued for quite some time.

16. Here Platonism is referred to under the banner of 'theories of meaning based upon notions of "real essence" and is called uninformative, together with theories based upon notions of 'mental idea', due to a lack of a criterion for two expressions having the same semantic property, in particular synonymy (Katz and Fodor 1962, 212).

17. Keith Allan claimed, rather proleptically, that the change had instead already happened in 1972:

K's Platonism can be traced back to his Semantic theory (1972). Earlier (1967, 129), he had described the conceptual content of a semantic marker as 'what is common to our individual ideas'. However, five years later he was saying that the concepts represented by semantic markers are not something that people have in mind on any one or any number of occasions: 'Concepts . . . are abstract entities. They do not belong to the conscious experience of anyone' $(1972,38)$. What $\mathrm{K}$ seems to intend here is that the content of a semantic marker is something like a Platonic Form (eîdos) or Idea (idéa). (Allan 1983, 678; cf. [1986] 2014, 89-90)

Allan overlooked the fact that the quote continues immediately: 'though they may be thought about' (Katz 1972, 38). The passage was probably written not five years but one year later (cf. note 7). Further, Allan failed to notice that Katz' early Democritean approach in 1972 ruled out condensed answers such as 'Platonic archetypes' $(1972,3,7)$, and that, on the very next page, Katz states that 'the question of what the ontological status of concepts and propositions is [. . .] will be left here without a final answer' $(1972,39)$.

18. The symbols for identity and non-identity are used here redundantly.

19. This distinction, between what he called expressional and non-expressional relations, first appears in Katz and Katz 1977, but is not spelt out in detail there.

20. Apart from Katz' own accounts, especially Katz (1998), I recommend Jacquette 1990 as an accessible account of the early Wittgenstein's problem.

21. I exclude here several further clauses to the definition of this operator, which are superfluous for our present purposes (cf. Katz 1972, 160-8).

22. Katz later extends this device to infinite such collections of markers which he calls 'antonymy sets' (Katz 1972, 312). 
23. ' $\mathrm{K}$ ' is an optional function that specifies that the variable should be filled by a more precisely determined semantic marker (Katz 1972, 104ff., 258ff.).

24. This formalism can be given an equivalent representation as a tree structure, with '(colour)' dominating '(red)' and 'A/(X)' (cf. Katz 1998, 567).

25. Full details can be found in Katz (1998 and 2004).

\section{REFERENCES}

Allan, K. (1983), 'Review of Language and Other Abstract Objects by Jerrold J. Katz', Language 59, no. 3: 678-83.

Allan, K. ([1986] 2014), Linguistic Meaning, Vol. 1, London: Routledge.

Begley, K. (2019), 'Review of Essays on Linguistic Realism', The Linguist List, 30.1644. Available Online: https://linguistlist.org/issues/30/30-1644.html

Carroll, L. ([1855] 1932), The Rectory Umbrella and Mischmasch, London: Cassell \& Co.

Chomsky, N. and Katz, J. J. (1974), 'What the linguist is talking about', The Journal of Philosophy 71, no. 12: 347-67.

Coliva, A. (2020), 'Logical atomism and Wittgenstein', in U. Zilioli (ed.), Atomism in Philosophy: A History from Antiquity to the Present, 301-11, London: Bloomsbury Academic.

Frege, G. ([1892] 1952), 'On concept and object', trans. P. T. Geach, in P. Geach and M. Black (eds), Translations from the Philosophical Writings of Gottlob Frege, 42-55, Oxford: Basil Blackwell \& Mott.

Frege, G. ([1918] 1968), 'The thought: A logical inquiry,' trans. A. M. and M. Quinton, in E. D. Klemke (ed.), Essays on Frege, 507-36, Urbana: University of Illinois Press.

Frege, G. ([1897] 1979), 'Logic', in H. Hermes, F. Kambartel and F. Kaulbach (eds), Gottlob Frege: Posthumous Writings, 126-51, Oxford: Basil Blackwell.

Frege, G. (1997), The Frege Reader, M. Beaney (ed.), Oxford: Blackwell.

Hacker, P. M. S. (1972), Insight and Illusion: Wittgenstein on Philosophy and the Metaphysics of Experience, Oxford: Oxford University Press.

Harman, G. (1974), 'Meaning and semantics', in M. K. Munitz and P. K. Unger (eds), Semantics and Philosophy, 1-16, New York: New York University Press.

Hertz, H. R. ([1892] 1893), Electric Waves: Being re-searches on the propagation of electric action with finite velocity through space, trans. D. E. Jones, London: MacMillan \& Co.

Jacquette, D. (1990), 'Wittgenstein and the color incompatibility problem', History of Philosophy Quarterly 7, no. 3: 353-65.

Kang, J. (2005), 'On the composition of the prototractatus', The Philosophical Quarterly (1950-), 55, no. 218: 1-20.

Katz, F. M. and Katz, J. J. (1977), 'Is necessity the mother of intension?', The Philosophical Review 86, no. 1: 70-96.

Katz, J. J. (1964), 'Semantic theory and the meaning of "Good”, The Journal of Philosophy 61, no. 23: 739-66.

Katz, J. J. (1965), 'The relevance of linguistics to philosophy', The Journal of Philosophy 62, no. 20: 590-602. 
Katz, J. J. (1966), The Philosophy of Language, New York: Harper \& Row.

Katz, J. J. (1967), 'Recent issues in semantic theory', Foundations of Language 3, no. 2: 124-94.

Katz, J. J. (1968a), 'The logic of questions', in B. Van Rootselaar and J. F. Staal (eds), Logic, Methodology and Philosophy of Science III, 463-93, Amsterdam: NorthHolland.

Katz, J. J. (1968b), Letter to Frits Staal, 28th of August, 1968. [In the possession of this author.]

Katz, J. J. ([1966] 1970), 'The semantic component of a linguistic description', in A. and K. Lehrer (eds), Theory of Meaning, 176-98, Englewood Cliffs: Prentice-Hall.

Katz, J. J. (1971), The Underlying Reality of Language and its Philosophical Import, New York: Harper \& Row.

Katz, J. J. (1972), Semantic Theory, New York: Harper \& Row.

Katz, J. J. (1975), 'Logic and language: An examination of recent criticisms of intensionalism', in K. Gunderson (ed.), Language, Mind and Knowledge, Minneapolis: University of Minnesota Press.

Katz, J. J. (1976), 'A hypothesis about the uniqueness of natural language', Annals of the New York Academy of Sciences 280: 33-41.

Katz, J. J. (1977), 'The real status of semantic representations', Linguistic Inquiry 8, no. 3: 559-84.

Katz, J. J. (1981), Language and Other Abstract Objects, Totowa: Rowman and Littlefield.

Katz, J. J. (1982), 'Common sense in semantics', Notre Dame Journal of Formal Logic 23, no. 2: 174-218.

Katz, J. J. (1986), Cogitations, Oxford: Oxford University Press.

Katz, J. J. (1990), The Metaphysics of Meaning, Cambridge, MA: The MIT Press.

Katz, J. J. (1992), ‘The new intensionalism', Mind, New Series, 101, no. 404: 689-719.

Katz, J. J. (1998), 'The problem in twentieth-century philosophy', The Journal of Philosophy 95, no. 11: 547-75.

Katz, J. J. (2004), Sense, Reference, and Philosophy, New York: Oxford University Press.

Katz, J. J. and Fodor, J. A. (1962), 'What's wrong with the philosophy of language?', Inquiry 5, nos. 1-4: 197-237.

Katz, J. J. and Fodor, J. A. (1963), 'The structure of a semantic theory', Language 39, no. 2: 170-210.

Katz, J. J. and Fodor, J. A. (1964), 'The structure of a semantic theory', in J. A. Fodor and J. J. Katz (eds), The Structure of Language: Readings in the Philosophy of Language, 479-518, Englewood Cliffs: Prentice-Hall.

Katz, J. J. and Postal, P. M. (1964), An Integrated Theory of Linguistic Descriptions, Cambridge, MA: The MIT Press.

Kienzler, W. (2011), 'Wittgenstein and Frege', in O. Kuusela and M. McGinn (eds), The Oxford Handbook of Wittgenstein, 79-104, Oxford: Oxford University Press.

Langendoen, D. T. (2010), 'Just how big are natural languages?', in H. van der Hulst (ed.), Recursion and Human Language, 139-46, Berlin: De Gruyter.

Langendoen, D. T. (2018), 'Languages as complete and distinct systems of reference', in C. Behme and M. Neef (eds), Essays on Linguistic Realism, 255-70, Amsterdam: John Benjamins. 
Lewis, D. (1970), 'General semantics', Synthese 22: 18-67.

McGuinness, B. (2002), 'Some pre-Tractatus Manuscripts', in Approaches to Wittgenstein, 259-69, London: Routledge.

Quine, W. V. O. (1953), 'The problem of meaning in linguistics', in From a Logical Point of View, 47-64, Cambridge, MA: Harvard University Press.

von Fintel, K. and Matthewson, L. (2008), 'Universals in semantics', The Linguistic Review 25: 139-201.

Wiggins, D. (1971), 'On sentence-sense, word-sense, and differences of word-sense: Towards a philosophical theory of dictionaries', in D. D. Steinberg and L. A. Jakobovits (eds), Semantics: An Interdisciplinary Reader in Philosophy, Linguistics and Psychology, 14-34, London: Cambridge University Press.

Williams, B. ([1972] 1993), Morality: An Introduction to Ethics, Cambridge: Cambridge University Press.

Wittgenstein, L. (1922), Tractatus Logico-Philosophicus, trans. F. P. Ramsey and C. K. Ogden, London: Routledge \& Kegan Paul.

Wittgenstein, L. (1971), 'Prototractatus: 4.0015', trans. D. F. Pears and B. F. McGuinness, University of Iowa Tractatus Map. Available Online: http://tractatus.lib.uiowa.edu

Wittgenstein, L. (2015), 'MS-104, 36 Facsimile', Bergen Nachlass Edition, Bodleian Libraries, Oxford, Wittgenstein Source. Available Online: http://www.wittgensteinso urce.org/BFE/Ms-104,36_f

Wolff, R. P. ([1970] 1998), In Defense of Anarchism, Berkeley: University of California Press.

Wolff, R. P. (2010), ‘The philosopher's stone', 30 April 2010, Blog. Available Online: http://robertpaulwolff.blogspot.com/2010/04/memoir-volume-two-chapter-three-seco nd.html

Wolff, R. P. (2019), ‘The philosopher’s stone', 12 April 2019, Blog. Available Online: http://robertpaulwolff.blogspot.com/2019/04/credit-where-credit-is-due.html

Zwicky, A. M. (1973), 'Linguistics as chemistry: The substance theory of semantic primes', in S. R. Anderson and P. Kiparsky (eds), A Festschrift for Morris Halle, 467-85, New York: Holt, Rinehart and Winston. 